\title{
Mixing requirement for ultra paste tailings
}

\author{
A Roshdieh ATC Williams Pty Ltd, Australia \\ S Javadi ATC Williams Pty Ltd, Australia \\ MPA Williams ATC Williams Pty Ltd, Australia
}

E Karamad IWMP NICICO, Iran

\begin{abstract}
A controlling variable for a thickened tailings scheme design is the beach slope that will be formed by the tailings as they deposit. The slope will be mainly related to the discharge flow rate and the slurry rheology. The latter will, in turn, be dependent on the solids concentration of the thickener underflow. A higher solids concentration can be achieved by combining thickening and filtration. The objective is to still maintain a slurry that is pumpable and self-distributing at the tailings storage facility (TSF), rather than having to rely on trucks or on conveyors and stacking systems to manage a 'cake', but one that will deposit at a steeper beach slope than can be achieved by thickening alone. The use of ultra paste has the potential to broaden the range of topographic conditions that will suit thickened tailings discharge.

The ultra paste thickened option is when a portion of the tailings is separated and dewatered in a more advanced dewatering unit (in this case filter presses). The filtered cake will then be re-mixed with the paste thickener underflow stream.

This paper presents a case study for a large copper mine in which underflow from a series of paste thickeners with a nominal tonnage of 3,660 tph at 59\% solids concentration would be mixed with 1,363 tph of filter cake at $80 \%$ solids concentration. The combined tailings (ultra paste) would be discharged equally into two open channels (flumes) at the combined solids concentration of $63.5 \%$.

The ultimate goal of adopting an 'ultra paste' scheme is to produce homogenous consistency tailings, hence proper mixing of the paste and filter cake has to occur. In this study based on a series of tests, the mixing requirement has been assessed. The study also covers a conceptual investigation of natural turbulent mixing (NTM) of the filtered tailings with paste thickened tailings and issues associated with the deposition of the combined tailings, the ultra paste, into the existing TSF.

In the conclusion, the study indicates that NTM can possibly occur only for the case in which the total tailings are discharged into one channel, which is not practical due to limitations with regards to tailings management. Hence, mechanical mixing has been recommended in this case.
\end{abstract}

Keywords: ultra paste, thickened tailings, beach slope, filter cake, mixing requirement

\section{Introduction}

\subsection{Background}

A large copper mine in the Middle East (Sarcheshmeh copper mine) is currently operating a thickened down valley discharge (DVD) scheme. The current tailings production rate is approximately $29 \mathrm{Mtpa}$. The mine utilises 12 existing paste thickeners to produce paste with a consistency of approximately 59\% ( $w / w)$ solids concentration (Javadi et al. 2015). The thickened tailings are distributed evenly into two arms (western and eastern streams) which eventually merge together just before the tailings embankment. Based on the rheological properties of the tailings, a maximum tailings beach slope of $1.75 \%$ is predicted (Roshdieh et al. 2015). 
Currently, the mine is planning for an expansion scheme. Upon the completion of this expansion scheme, the nominal tailings production will increase from $29 \mathrm{Mtpa}$ (3,660 tph) to $39.8 \mathrm{Mtpa}$ (5,023 tph); an increase of $10.8 \mathrm{Mtpa}(1,363 \mathrm{tph})$. Several tailings management alternatives have been considered. This includes various dewatering technologies (i.e. utilisation of additional thickeners or filters). Water scarcity in the region can justify the capital and operating costs of the utilisation of more sophisticated dewatering technologies (Roshdieh et al. 2016). However, since $1224 \mathrm{~m}$ diameter paste thickeners are already utilised (MacNamara et al. 2011), the huge operating cost of material handling of the cake (transportation and distribution) could be a prohibiting factor in the utilisation of the filtration option (in this case filter presses).

An alternative option that has been considered in this project is the utilisation of filter presses for the additional tailings tonnage but instead of transportation of the filter cake in a separate distribution system, the filter cake can be re-mixed with the underflow from the paste thickeners to produce a combined solids concentration of $63.5 \%$. The mixture is called 'ultra paste' tailings and can provide the following advantages:

1. By re-mixing the filter cake with the underflow from the paste thickeners, the large annual operating cost of filter cake transportation and distribution can be eliminated.

2. The filter cake can be disposed of in the same tailings storage facility (TSF). Otherwise, a separate dry stack had to be considered for the filter cake.

3. The combined tailings will have a higher solids concentration (in comparison to the underflow from the paste thickeners) and hence higher rheological properties. As a result, the deposited tailings will settle at a steeper beach slope. This will result in higher efficiency within the TSF. In this case, the predicted maximum beach slope for the ultra paste tailings is $2 \%$, while if the ultra paste scheme is not utilised and with the increased tonnage, the beach slope at $59 \%$ solids concentration would have been $1.30 \%$. This would have a big impact on the size of the required embankment.

By utilising the ultra paste scheme, an overall water saving of $2.2 \mathrm{Mm}^{3} / \mathrm{yr}$ could be expected.

Figure 1 illustrates a simplified diagram of the proposed ultra paste scheme in this case.

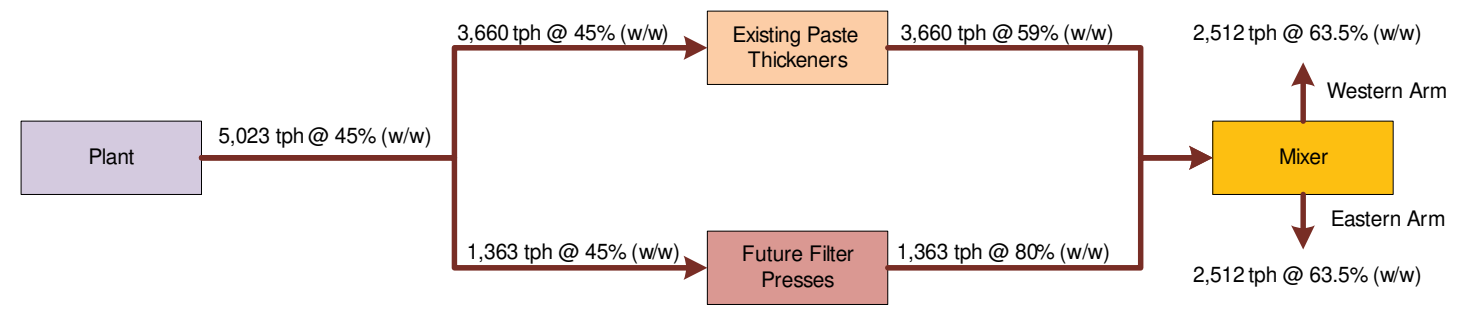

\section{Figure 1 Simplified flow diagram showing the proposed ultra paste scheme}

Another ultra paste alternative could be the utilisation of less sophisticated filtration units, such as vacuum belt filters to produce the tailings at the required consistency (63-64\%) directly. This option is not applicable in this case and is not covered in the present article but could be a viable alternative in different circumstances.

\subsection{Scope}

As outlined above, the underflow from the paste thickeners has to be sufficiently well-mixed with the filter cake to produce a homogeneous combined tailings to be discharged in two streams on the western and eastern sides of the dewatering plant platform, as shown in Figure 2. In this case, two potential mixing options have been investigated:

- Mechanical mixing.

- Natural turbulent mixing in the discharge streams. 
To be able to make the assessment, mixing requirements, namely the mixing time and the required power for these specific tailings, have to be defined. Hence, two sets of tests have been undertaken to define the properties of the tailings and define the mixing requirements.

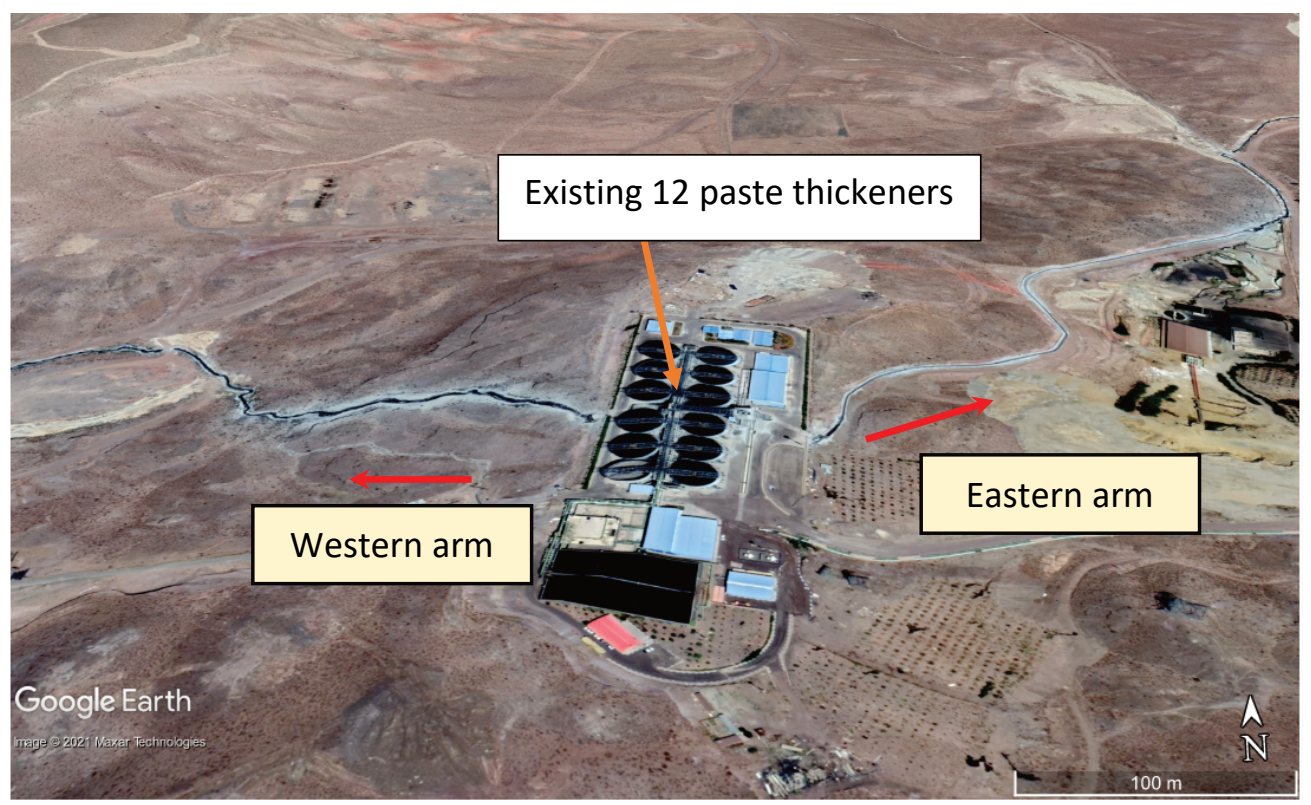

\section{Figure 2 Dewatering platform and discharge streams}

\section{Testwork}

\subsection{Tailings testing}

The tailings testing involved analysis and measurement of particle size distribution (PSD), Atterberg limits, tailings specific gravity, and tailings rheological properties. The key tailings classification properties and rheological properties are presented in Tables 1 and 2, respectively.

The rheological testing was carried out using a Thermo Haake VT550 Viscometer. An MV2P Couette flow (bob in cup) sensor system was used for the measurement of flow curve rheology at ATC Williams laboratory in Melbourne. However, at high solids concentrations, the rheometer could not provide sufficient torque to obtain the rheological parameters. Therefore, a few of the rheological tests were conducted using a HR3 TA instrument rheometer at the Rheology and Material Processing Centre (RMPC) of RMIT University.

Table 1 Key tailings classification properties

\begin{tabular}{ll}
\hline Parameter & Quantity \\
\hline Solids specific gravity & 2.85 \\
Tailings Atterberg limits & \\
Liquid limit & $25 \%$ \\
Plastic limit & $22 \%$ \\
Plasticity index & $3 \%$ \\
Tailings particle size & \\
$d_{80}$ & 110 micron \\
$d_{50}$ & 35 micron \\
$d_{20}$ & 4 micron \\
\hline
\end{tabular}


Table 2 Key tailings rheological properties (sheared samples)

\begin{tabular}{lcc}
\hline Solids & \multicolumn{2}{c}{ Bingham plastic } \\
& $\tau_{\mathrm{y}}(\mathrm{Pa})$ & $\boldsymbol{K}_{\mathrm{b}}$ (m.Pas) \\
\hline 49.95 & 9.62 & 35.98 \\
55.59 & 17.21 & 65.47 \\
58.23 & 36.12 & 77.20 \\
61.20 & 54.50 & 150.89 \\
64.14 & 91.65 & 247.43 \\
67.02 & 160.04 & 562.85 \\
\hline
\end{tabular}

As seen in Table 2, the rheological testing shows that the sheared sample's yield stress exceeds the range of 50-100 Pa which is often expected from paste thickening at solids concentration greater than $60-65 \%$. This proves that the ultimate achievable solids concentration by paste thickener for this material would not be more than the $60-65 \%$ that is already observed in current operation. Therefore, for any further dewatering, an ultra paste or filtration is required.

\subsection{Mixing testing}

A set of preliminary tests were carried out to evaluate the general mixing requirements of the filter cake with paste tailings. The testing objectives were to define the mixing power and time, and to confirm if the filtered and paste tailings can be mixed within a viable mixing time. Figure 3 shows the mixing equipment that was utilised for this purpose. The mixer is a Heidolp RZR unit equipped with a variable speed drive.

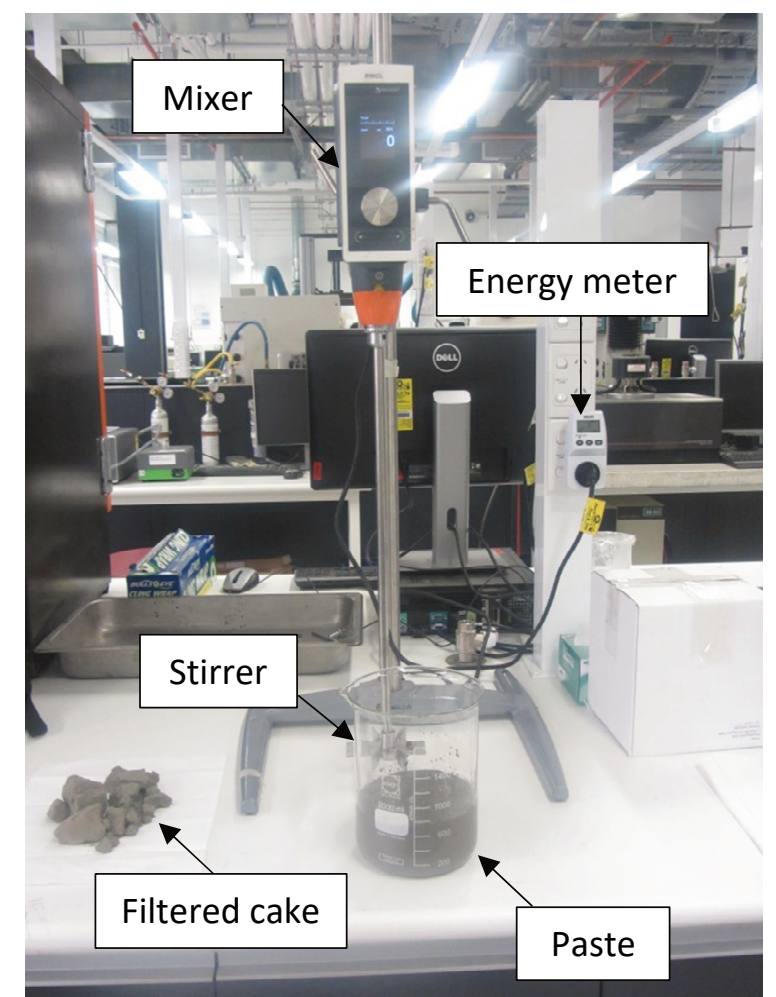

Figure 3 Mixing test arrangement using Heidolp RZR mixer 
In Table 3, the details of the mixing test conditions are presented. The mixer was filled with 0.35 parts of the filtered cake and 0.65 parts of paste tailings. The mixer was operated for four minutes and four samples were taken during the mixing (one sample at every minute). The samples were taken to measure the mixture yield stress. The sample was poured back into the mixer after the yield stresses were measured. The rheology of the material was measured using a HR3 TA instrument rheometer fitted with bob and cup geometry.

\section{Table 3 Mixing testing conditions details}

\begin{tabular}{lll}
\hline Item & Quantity & Unit \\
\hline Mixer speed & 225 & $\mathrm{RPM}$ \\
Stirrer tip speed & 0.94 & $\mathrm{~m} / \mathrm{s}$ \\
Mixing time & $1-4$ & $\mathrm{~min}$ \\
Weight of tailings cake & 313 & $\mathrm{gr}$ \\
Cake solids content & 80 & $\%$ \\
Weight of tailings paste & 1,211 & $\mathrm{gr}$ \\
Paste solids content & 59 & $\%$ \\
Mixer volume & $1.447 \times 10^{-3}$ & $\mathrm{~m}^{3}$ \\
\hline
\end{tabular}

Throughout the mixing, the instantaneous absorbed power by the mixer has been recorded. The recorded power data is presented in Figure 4. It is apparent that the absorbed power declines with time in the first 70-80 seconds of testing until it reaches a steady condition where it remains constant. This phenomenon can be explained as follows: the filtered cake structure was being broken down initially until a homogenous mixture was achieved. On this basis, a mixing time of 80 seconds is assumed to be required. Having said that, the retention time could also be dependent on the type and geometry of the stirrer and the mixer, and other factor such as mixing intensity.

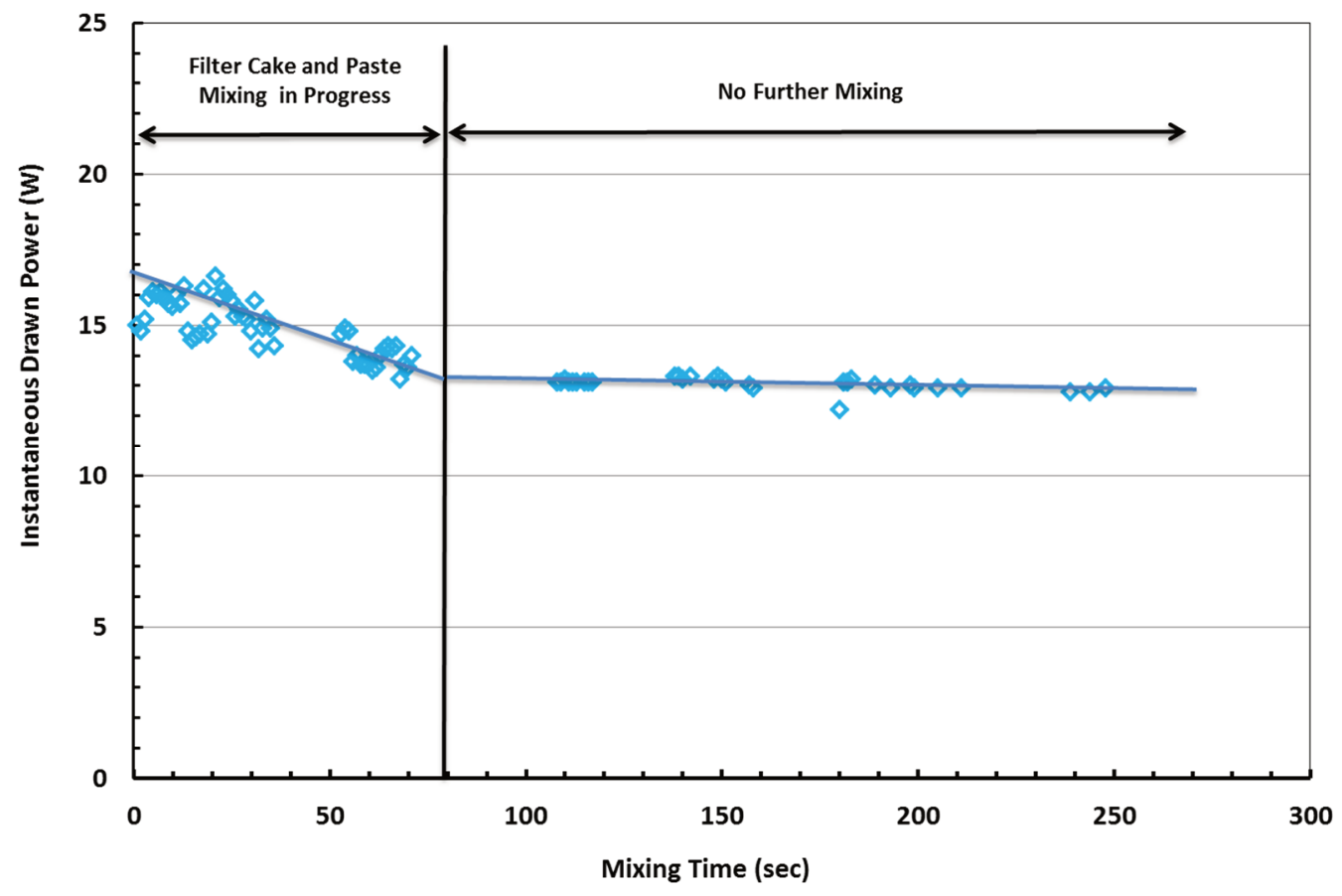

Figure 4 Instantaneous absorbed power by the mixer 
Figure 5, on the other hand, illustrates the cumulative energy that is absorbed by the mixer. Given 80 seconds mixing time, the actual total consumed energy for the mixer is estimated to be $0.40 \mathrm{kWh} / \mathrm{m}^{3}$.

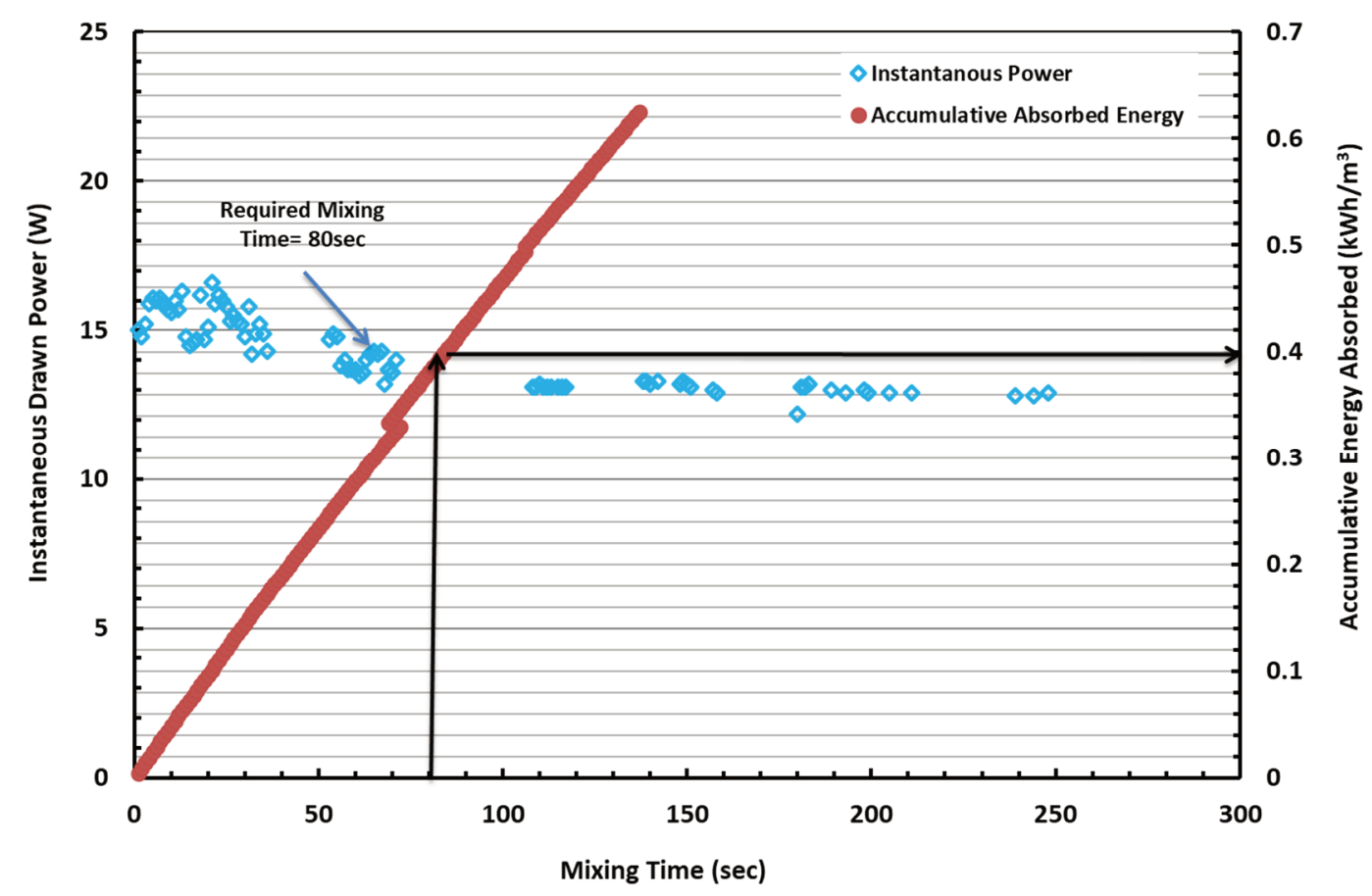

Figure 5 Mixing energy versus mixing time

Referring to Figures 4 and 5, the maximum required power to mix the combined tailings is $17 \mathrm{~W}$. The average velocity gradient has been estimated using Equation 1.

$$
G=\sqrt{\frac{P}{\mu V}}
$$

where:

$$
\begin{aligned}
\mathrm{G} & =\text { average velocity gradient } \mathrm{1} / \mathrm{s} . \\
\mathrm{P} & =\text { power requirement, } \mathrm{W} . \\
\mu & =\text { dynamic viscosity, } \mathrm{Pa} . \mathrm{s} . \\
\mathrm{V} & =\text { Volume, } \mathrm{m}^{3} .
\end{aligned}
$$

Based on the results of the tests, the average velocity gradient of approximately $2501 / \mathrm{s}$ is estimated. As mentioned earlier, the test results also suggest that the required retention time is approximately 80 seconds.

\section{$3 \quad$ Mixing alternatives}

\subsection{Mechanical mixing}

The selection of the mechanical mixer for this project was undertaken in conjunction with Outotec. The proposed system involves eight continuous single shaft mixers operating in parallel. Each mixer has a live volume of $12.5 \mathrm{~m}^{3}$ and is fitted with a $250 \mathrm{~kW}$ electromotor. A retention time of slightly more than 60 seconds would be provided by the proposed mixers. The mixing energy at the design volumetric flow rate is $0.39 \mathrm{kWh} / \mathrm{m}^{3}$. This is based on a separate mixing test that was undertaken by Outotec at their laboratories in Australia. 


\subsection{Natural turbulent mixing}

\subsubsection{General and assumptions}

Natural turbulent mixing (NTM) could be an alternative method for the mixing of the filter cake with the paste tailings if the energy requirement for mixing can be achieved. It is postulated that the mixing of the two phases could be achieved by turbulent mixing provided that the carrier fluid generates a sufficiently chaotic and turbulent regime for a certain period of time. It is assumed that the eddies and vortices formed by the turbulent regime would break the filter cake structure down so that a homogeneous or semi-homogenous mixture would eventually form.

It should be noted that, in this article, turbulent mixing is denoted by NTM as this flow regime is formed with the available head provided by the natural terrain topography.

NTM is in an area of fluid mechanics for which a complete theoretical modelling approach has not been fully developed to date. Turbulent flow modelling, even for a Newtonian single-phase fluid in a very simple geometry such as one with circular boundaries, is not fully understood as yet. It becomes even more complicated when dealing with a non-Newtonian multiphase fluid flow in an unconfined channel. The uncertainties associated with the underlying motion equations and our ability to solve the fundamental physics problem forces us to only evaluate the mixing process from a macroscopic perspective.

On this basis, given the limited theoretical knowledge available, the NTM option has been investigated based on mixing energy rather than mixing turbulence modelling. To undertake this, the available natural energy from the gravity flow is calculated and is then compared with the mechanical mixing energy requirement.

The calculations are based on the following assumptions:

1. Natural mixing is achievable if the flow is transitional or turbulent. Therefore, for any section of the channel where the flow is in the laminar flow regime, it is assumed that natural mixing does not occur.

2. The solids concentration of the carrier fluid increases linearly along the channel from $59 \%$ at the head of the channel (i.e. paste and filtered cake tailings at the discharge point) to $63-64 \%$ at the other end of the channel (i.e. complete homogeneous mixing).

3. Natural mixing is assessed in the existing concrete channel in the eastern arm, and the existing natural channel in the western arm. Other routes, with different slopes, are not evaluated in this study.

4. In this analysis, the effect of flow disturbance with an external object to create additional turbulence has not been evaluated.

5. Combined tailings discharge into the TSF would be based on one of the following scenarios:

a. Total tailings discharge: total combined tailings would be discharged either into the western or eastern arms separately.

b. Split tailings discharge: combined tailings would be split between the western and the eastern arms, and the discharge into both arms would take place simultaneously.

\subsubsection{Methodology}

In a channel carrying fluids, the absorbed energy by the material flowing down the channel depends on the channel profile. Figure 6 shows the channel profiles from the discharge point to the head of the beach for the western and eastern arms. 


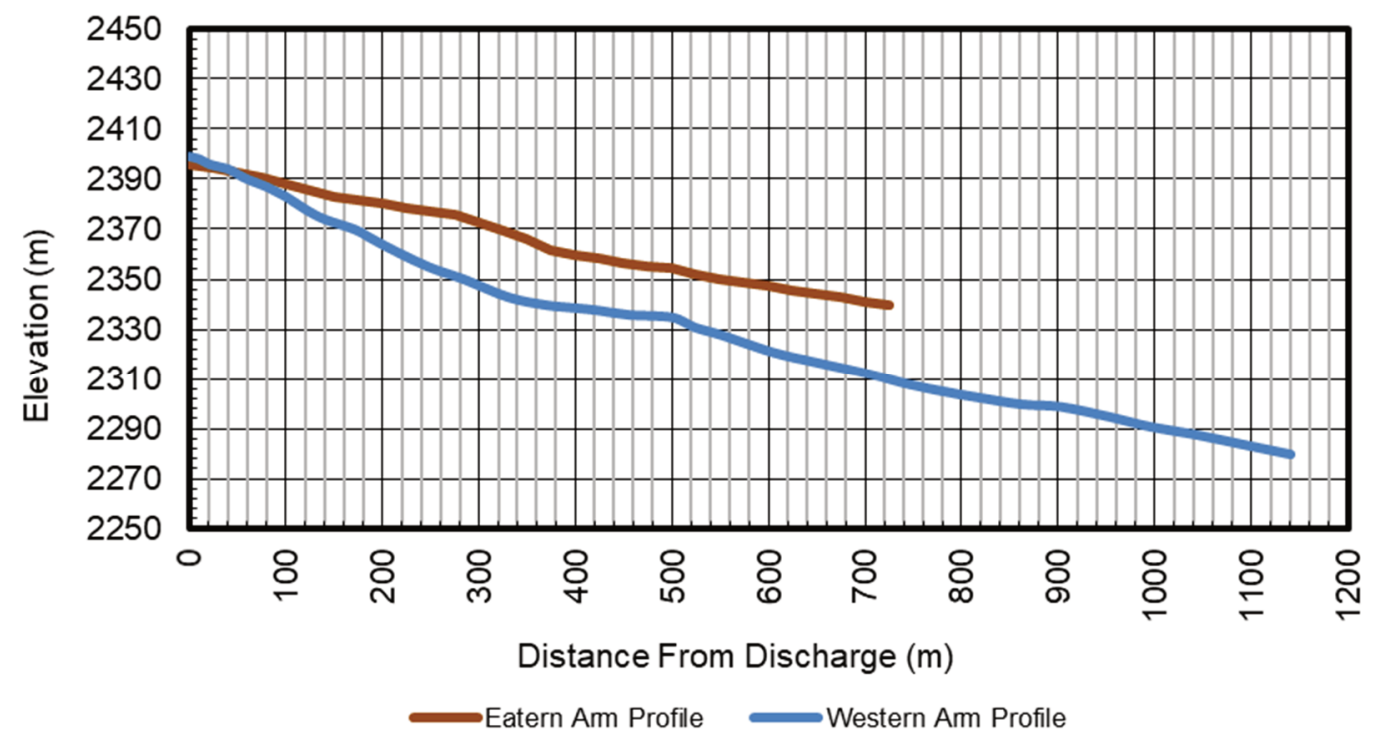

Figure 6 Western and eastern channel profiles

Based on assumption number 1 in Section 3.2.1, the absorbed energy will break the filter cake if the flow regime is not laminar. In fact, in the laminar flow regime, the absorbed energy is only sufficient to move the material down the channel and there would not be any extra energy left to create turbulence. On this basis, the amount of available energy for the mixing would be the sum of the energy from the sections of the channel in which the flow regime is turbulent.

In order to determine the mixing regime, the channel is divided into $100 \mathrm{~m}$ long sections. For each section, depending on the solids concentration of the carrier fluid, a critical slope is predicted and if the channel slope is greater than the critical slope, a turbulent flow regime is expected to occur.

The energy for each section is defined as presented in Equation 2:

$$
E_{i}=\frac{\rho_{i} g H_{i}}{3.6 \times 10^{6}}
$$

where:

$$
\begin{aligned}
& E_{i}=\text { channel energy in section } \mathrm{i}, \mathrm{kWh} / \mathrm{m}^{3} . \\
& \rho_{i} \quad=\text { carrier fluid density in section } \mathrm{i}, \mathrm{kg} / \mathrm{m}^{3} . \\
& g \quad=\text { gravitational acceleration, } \mathrm{m} / \mathrm{s}^{2} . \\
& H_{i} \quad=\text { section } \mathrm{i} \text { drop, } \mathrm{m} .
\end{aligned}
$$

\subsubsection{Results and discussions}

In Figures 7, 8 and 9 the $X$-axis is the distance from the discharge point in either the western or the eastern arms, and the $\mathrm{Y}$-axis is the slope. The available slope in each case is shown in green bars and the critical slope is shown in red bars. As mentioned above, at any section where the available slope (the green bar) is larger than the critical slope (the red bar), it is assumed that mixing would occur and the energy is estimated using Equation 2.

In Figure 7, the available slope in the channel is shown next to the predicted critical slope for the western arm in the case when all the tailings (29 Mtpa of paste and $10.8 \mathrm{Mtpa}$ of filter cake) is discharged into this arm only. In this arm, the mixing is anticipated to occur in the first $700 \mathrm{~m}$ of the channel (except for chainage 400 to $500 \mathrm{~m}$ ) where the available slope is greater than the critical slope. The flow regime in this section would be turbulent while in the last $450 \mathrm{~m}$ of the channel length, a laminar flow regime is expected to occur. The total absorbed energy by the tailings in this reach is estimated to be $1.6 \mathrm{MW}$, which is equal to $0.36 \mathrm{kWh} / \mathrm{m}^{3}$. 


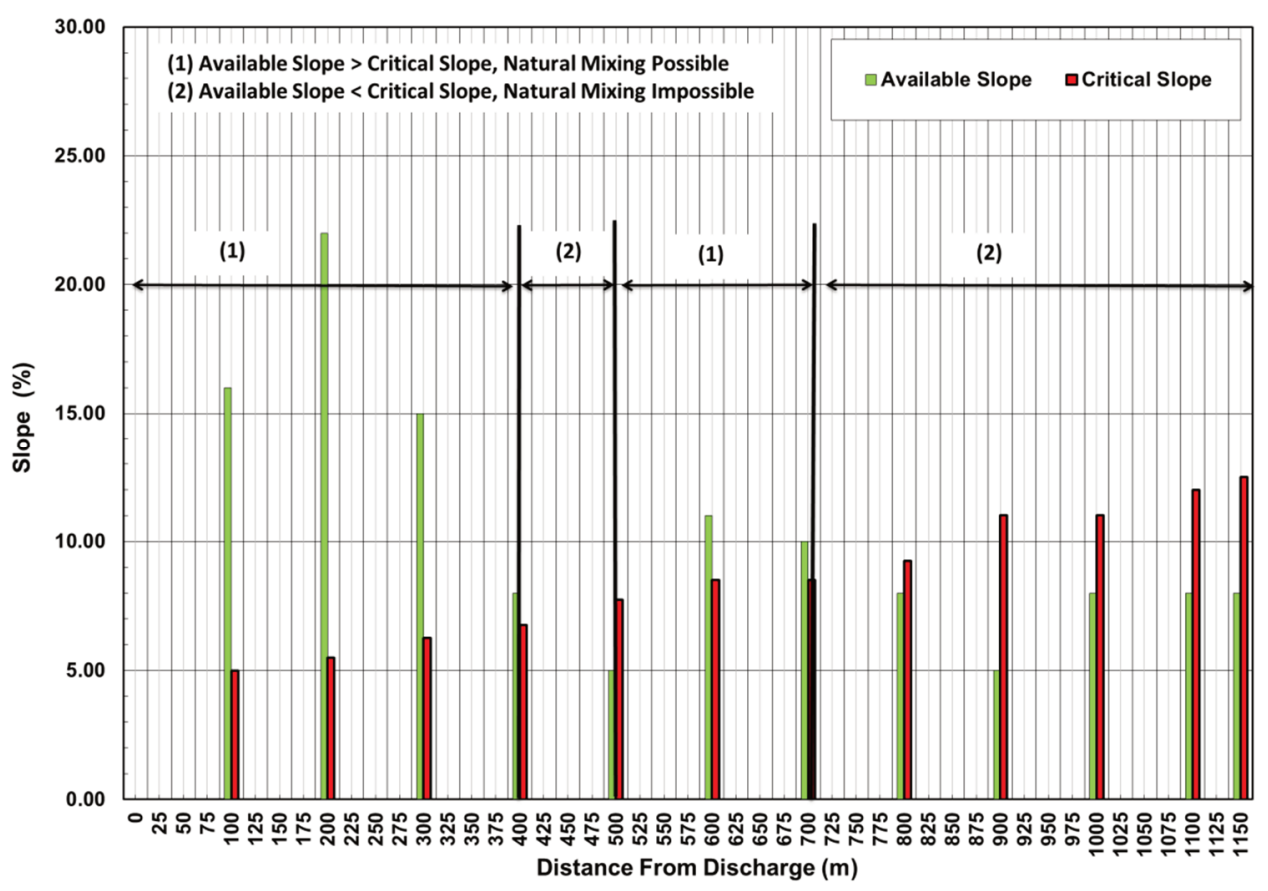

Figure 7 Western arm mixing - total tailings

A similar analysis has been undertaken for the eastern arm and the results are shown in Figure 8 . This arm is flatter and shorter compared to the western arm and the mixed tailings would flow through a concrete channel with a trapezoidal cross-section which has been in operation since 2012 . The channel is $725 \mathrm{~m}$ long and for the total tailings discharge, the NTM is anticipated to occur in the first $500 \mathrm{~m}$ of the channel. In this case, the total available absorbed energy by the tailings would be $1.15 \mathrm{MW}$ which is equal to $0.16 \mathrm{kWh} / \mathrm{m}^{3}$.

Although the available energy in the western arm appears to be close to the target-required energy of $0.4 \mathrm{kWh} / \mathrm{m}^{3}$ for mixing, this case (i.e. discharge of $100 \%$ of the combined paste and cake either into the western or the eastern arm) is not seen to be practical. The main reason is that in the tailings deposition plans, both arms have to be utilised at the same time. Thus this option does not appear to present a viable alternative.

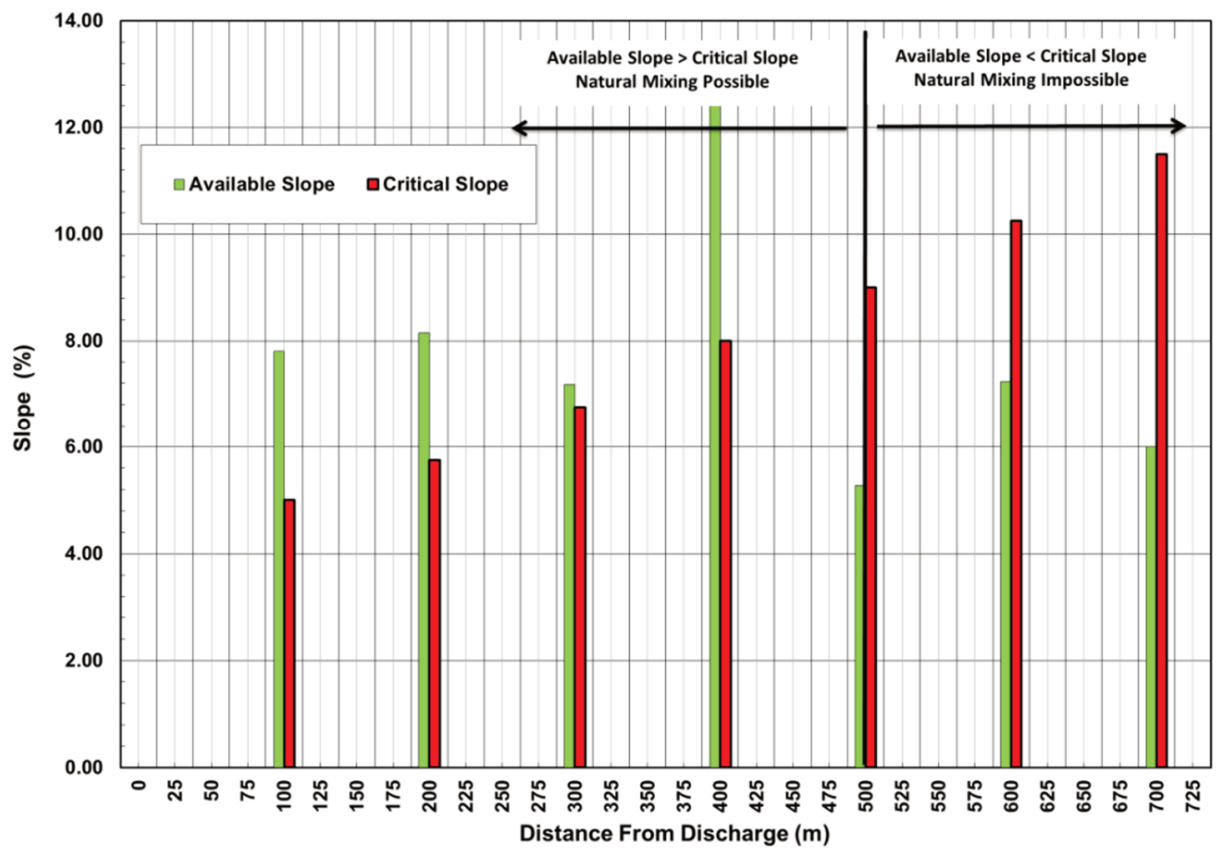

Figure 8 Eastern arm mixing - total tailings 
There is another case in which paste and cake are combined and split equally into the western and eastern arms simultaneously. Figure 9 shows the predicted transitional slope with the available slope along the western arm for this case. As can be seen, the NTM is anticipated to occur in the first $400 \mathrm{~m}$ of the channel. In this case, the total available energy would be $0.5 \mathrm{~kW}$ which equates to $0.23 \mathrm{kWh} / \mathrm{m}^{3}$.

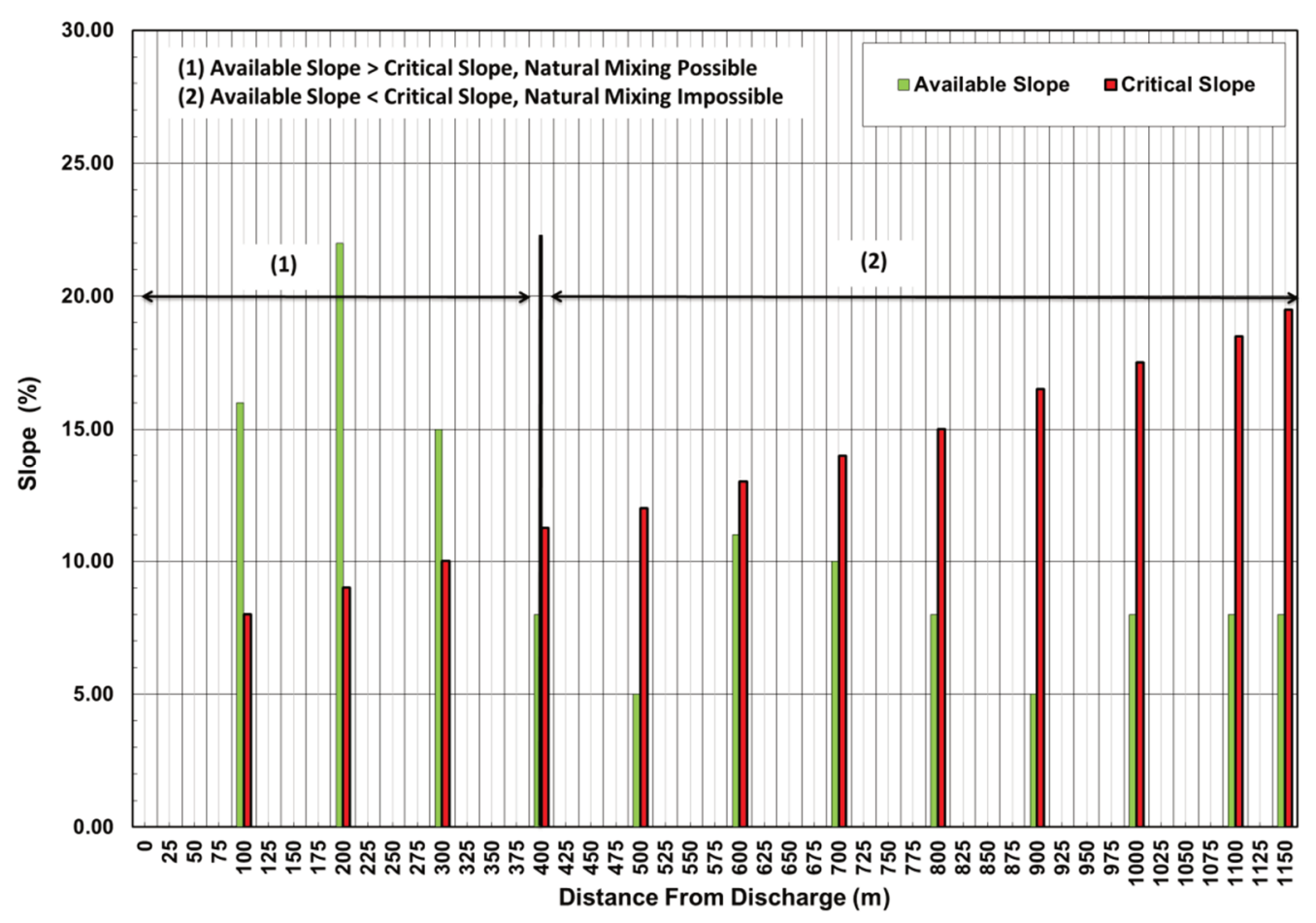

Figure 9 Western arm mixing - split tailings

It is apparent that the available energy, in this case, is lower than the required mixing energy for a complete mix in the western arm. With the same logic, since the average slope and the length of the eastern arm is less than that of the western arm, it can be concluded that the available energy in the eastern arm would also not be sufficient for the mixing of paste and cake.

In Table 4 a comparison of the NTM available energy with the required energy for complete mechanical mixing is presented. Even though the mixing mechanisms in the mechanical and natural systems are quite different, this comparison is made to present at least a preliminary indication as to whether the available energy from natural mixing could accommodate the complete mixing requirement.

Table 4 Mixing energy comparison

\begin{tabular}{lll}
\hline Item & Total energy MW & Energy rate $\mathbf{k W h} / \mathbf{m}^{\mathbf{3}}$ \\
\hline Mechanical mixing & 1.80 & 0.40 \\
Natural mixing western arm (total tailings discharge) & 1.60 & 0.36 \\
Natural mixing eastern arm (total tailings discharge) & 1.15 & 0.16 \\
Natural mixing western arm (split tailings discharge) & 0.50 & 0.23 \\
\hline
\end{tabular}

It is shown that the only case in which NTM is likely to be successful is total tailings discharge in the western arm. The available energy for this case is just marginally lower than that which was recommended for mechanical mixing. It implies that, given the availability of the energy, NTM is possibly achievable while directing the total tailings to the western arm down to the TSF. On the other hand, NTM would not occur for the other cases (i.e. total tailings discharge into the eastern arm or split tailings discharge). 


\section{Conclusion}

The following is concluded as the result of the present study:

1. The ultra paste option could be a viable tailings management strategy.

2. Based on the findings of the present study, the required mixing energy for tailings with similar properties would be $0.39 \mathrm{kWh} / \mathrm{m}^{3}$.

3. Based on the results of the tests, the average velocity gradient of approximately $2501 / \mathrm{s}$ is required with a retention time of approximately 80 seconds for similar tailings.

4. The study shows that NTM could only possibly be feasible for total tailings discharge in the western arm. This is not consistent with the overall tailings management requirement in the TSF in this case.

5. The phenomenon of natural mixing is not yet able to be fully analysed and hence, in the absence of theoretical proofs, an experimental trial test is recommended for the evaluation of this approach in a real-life mining situation.

\section{Acknowledgement}

The authors extend their gratitude to Mr Seif, the client representative at the time of the study. The authors also thank Mr Mathew Revel from Outotec and Mr Liam MacNamara from FLSmidth for their assistance and consultation.

\section{References}

Javadi, S, Pirouz, B, Williams, P, Zarabadi, A \& Seif, HR 2015, 'Sarcheshmeh Copper Mine paste plant design, start-up and early operation overview', in R Jewell \& AB Fourie (eds), Paste 2015: Proceedings of the 18th International Seminar on Paste and Thickened Tailings, Australian Centre for Geomechanics, Perth, pp. 107-115, https://doi.org/10.36487/ACG_rep/1504_06_Javadi

MacNamara, L, Khoshniaz, N \& Hashemi, S 2011, 'The Sarcheshmeh thickened tailings disposal project', in R Jewell \& AB Fourie (eds), Paste 2011: Proceedings of the 14th International Seminar on Paste and Thickened Tailings, Australian Centre for Geomechanics, Perth, Australia, pp. 237-243, https://doi.org/10.36487/ACG_rep/1104_22_MacNamara

Roshdieh, A, Seddon, KD \& Pavissich, C 2016, 'Optimization of tailings management schemes: comparison of tailings filtration and paste', in S Barrera \& R Jewell (eds), Paste 2016: Proceedings of the 19th International Seminar on Paste and Thickened Tailings, Gecamin, Santiago, pp. 170-180.

Roshdieh, A, Williams, P \& Seddon, KD 2015, 'The Sarcheshmeh thickened tailings scheme - a case study', in R Jewell \& AB Fourie (eds), Paste 2015: Proceedings of the 18th International Seminar on Paste and Thickened Tailings, Australian Centre for Geomechanics, Perth, pp. 587-595, https://doi.org/10.36487/ACG_rep/1504_45_Roshdieh 
